\title{
PRODUÇÃO E HETEROSE EM CRUZAMENTOS ENTRE LINHAGENS DE PEPINO DO GRUPO CAIPIRA
}

\author{
AMANDA REGINA GODOY ( $\left.{ }^{2}\right)$; ANDRÉA REIKO OLIVEIRA HIGUTI ( $\left.{ }^{2}\right)$; \\ ANTONIO ISMAEL INÁCIO CARDOSO $\left({ }^{2 *}\right)$
}

\begin{abstract}
RESUMO
O objetivo deste trabalho foi avaliar a produção de oito linhagens de pepino do grupo caipira cruzadas no esquema de dialelo parcial interpopulacional $(4 \times 4)$, obtendo-se 16 híbridos experimentais, em condições de cultivo protegido com polinização aberta por insetos e também estimar a heterose dos híbridos experimentais. O delineamento experimental foi em blocos ao acaso, com 27 tratamentos: 16 híbridos experimentais, três híbridos comerciais (Safira, AG-221 e Guarani), quatro linhagens $S_{5}$ da população SHS e quatro linhagens $S_{4}$ da população $G H$, quatro repetições e seis plantas por parcela. As características avaliadas foram: número e massa total de frutos por planta, número e massa de frutos comerciais por planta e porcentagem de frutos comerciais. Foram estimadas as heteroses e as heterobeltioses. Quanto aos híbridos experimentais avaliados destacam-se os híbridos H35 e H43 para produção. Foram obtidas heteroses positivas demonstrando a vantagem dos híbridos experimentais em relação às linhagens e, geralmente, em relação ao genitor superior.
\end{abstract}

Palavras-chave: Cucumis sativus L., produção, melhoramento.

\section{ABSTRACT \\ YIELD AND HETEROSIS IN CUCUMBER INBRED LINES CROSSES}

The objective of this work was to evaluate yield of eight cucumber inbred lines and heterosis of hybrids from intercrosses parcial diallel $(4 \times 4)$, in non heated green house allowed open pollination by insects. The experimental design was randomized blocks with 27 treatments: 16 experimental hybrids, three commercial hybrids (Safira, AG-221 and Guarani), four $S_{5}$ lines from population SHS and four $S_{4}$ lines from population $\mathrm{GH}$, with four replicates and six plants per plot. The following traits were evaluated: total fruit number and fruit weight per plant, commercial fruit number and commercial fruit weight per plant and percentage of commercial fruits. Heterosis and superiority in relation to superior parent were estimated. Experimental hybrids H35 and H43 had the highest yield. Both positive heterosis of hybrids over lines, and general heterosis, in relation to superior parental were obtained.

Key words: Cucumis sativus, yield, breeding.

(1) Recebido para publicação em 22 de novembro de 2007 e aceito em 9 de maio de 2008.

$\left({ }^{2}\right)$ Departamento de Produção Vegetal, Faculdade de Ciências Agronômicas, Universidade Estadual Paulista, Caixa Postal 237, 18603-970 Botucatu (SP). E-mail: ismaeldh@fca.unesp.br $\left(^{*}\right)$ Autor correspondente. 


\section{INTRODUÇÃO}

O pepino é uma hortaliça pertencente à família Cucurbitaceae, gênero Cucumis, espécie C. sativus L., com centro de origem na Índia (WhitAKer e Davis, 1962).

A espécie não se adapta ao cultivo sob baixas temperaturas, sendo o desenvolvimento da planta favorecido por temperaturas médias superiores a 20 ${ }^{\circ} \mathrm{C}$ (LOWER e EDWARDS, 1986). Temperaturas inferiores a $20{ }^{\circ} \mathrm{C}$ afetam a absorção de água e nutrientes pelo sistema radicular (ROBINSON e DECKER-WALTERS, 1999). Esse foi um dos motivos pelos quais os produtores passaram a cultivar pepino em ambiente protegido a partir da década de 80 (CAÑIZARES, 1998). Entre as cucurbitáceas, o pepino é a espécie mais cultivada em ambiente protegido em todo o mundo (Robinson e Decker-Walters, 1999).

O uso de sementes híbridas na produção comercial de hortaliças é hoje prática comum nos países desenvolvidos e naqueles em acelerado processo de desenvolvimento. Embora alógama, o pepino geralmente não possui perda de vigor em função da endogamia, porém é possível observar heterose destacada. Desse modo, a utilização de híbridos $\mathrm{F}_{1}$ é motivada pelas vantagens oferecidas aos produtores e consumidores, destacando-se aumento da produtividade, precocidade, mais uniformidade, melhor padronização e qualidade de frutos, maior resistência a pragas e doenças e estabilidade de comportamento sob condições ambientais variáveis (Maluf, 2001). Segundo Viggiano (1994), também o baixo custo da semente em relação ao custo total da cultura facilitou a introdução de híbridos de pepino no Brasil.

A superioridade de híbridos $\mathrm{F}_{1}$ em pepino foi constatada há nove décadas, em 1916, por Hayes e Jones, citados por FILGUEIRA et al. (1986). Nesta ocasião, foi verificada a presença de heterose para produção de frutos e número de frutos por planta. Entretanto, o primeiro híbrido comercial de pepino, Burpee Hybrid, foi obtido por O. Shifriss em 1945, e introduzido pela Burpee Seed Company (Robinson e DeCKer-Walters, 1999).

Já foram relatadas heteroses significativas para diversas características vegetativas e reprodutivas em pepino. GHADERI e LOWER (1978) observaram heterose principalmente em características vegetativas. Já Delaney e Lower (1987) observaram heterose significativa para produção, número de ramificações e comprimento de entrenó.

Heterose positiva foi relatada em um dialelo entre quatro linhagens de pepino por Li et al. (1995) para produção total, produção precoce, número de frutos, massa média de frutos e área foliar, e heterose negativa para comprimento de haste. Cur et al. (1992), estudando um dialelo parcial $4 \times 4$, reportaram maior precocidade nos híbridos quando comparados aos respectivos genitores. Também CARDOSO (2006) relatou heterose elevada para produção de frutos em híbridos experimentais de pepino do tipo caipira, assim como para pepino do tipo japonês (CARDOSO, 2007).

Apesar da heterose e endogamia serem relatadas para pepino indústria, CRAMER e WEHNER (1999) relataram que há possibilidade de se obter linhagens tão boas quanto os híbridos, com baixa depressão por endogamia.

Segundo FeHr (1987), o desenvolvimento de linhagens endogâmicas e a obtenção de híbridos comerciais, a partir de populações segregantes possuem seis fases: formação de uma população segregante; endogamia de indivíduos da população até o nível adequado de homozigose; avaliação do desempenho das linhagens per se; avaliação da capacidade geral de combinação das linhagens; avaliação das linhagens em híbridos comerciais potenciais; produção de sementes híbridas a partir de linhagens endogâmicas.

Portanto, um dos primeiros passos em um programa de melhoramento visando à obtenção de híbridos é a escolha das populações de onde se pretende extrair as linhagens. Depois são obtidas as linhagens e, com estas, os híbridos experimentais.

O objetivo deste trabalho foi avaliar a produção de oito linhagens de pepino do grupo caipira cruzadas no esquema dialelo parcial interpopulacional, obtendo-se 16 híbridos experimentais, em condições de cultivo protegido com polinização aberta por insetos e também estimar a heterose dos híbridos experimentais.

\section{MATERIAL E MÉTODOS}

O experimento foi desenvolvido na Fazenda Experimental São Manuel, pertencente à Faculdade de Ciências Agronômicas (FCA) da Universidade Estadual Paulista (UNESP), Campus de Botucatu, localizada no município de São Manuel (SP). Realizado em ambiente protegido, estrutura tipo arco, com 7,0m de largura por 20,0m de comprimento e pé direito de $1,8 \mathrm{~m}$, com cobertura de polietileno transparente de $150 \mathrm{~mm}$ de espessura. As laterais permaneceram abertas, possibilitando a entrada de insetos polinizadores.

As linhagens estudadas foram obtidas de duas populações. A primeira população foi obtida mediante 
o cruzamento entre os híbridos Safira (grupo caipira) e Hatem (grupo holandês). O híbrido resultante foi retrocruzado com 'Safira' obtendo-se a população (Safira $\times$ Hatem) x Safira $\mathrm{F}_{1} \mathrm{RC}_{1}$. Plantas desta população foram intercruzadas para a obtenção da população $\mathrm{F}_{2}$, denominada de população SHS. Plantas ao acaso desta população foram autofecundadas por cinco gerações pelo método Single Seed Descent $=$ Descendência de Semente Única (SSD), de acordo com Brim (1966), até a obtenção de linhagens $S_{5}$.

A segunda população foi obtida mediante o cruzamento entre os híbridos Guarani (grupo caipira) e Hatem. Deste cruzamento, obteve-se a população (Guarani x Hatem) $F_{1}$. Plantas desta população foram intercruzadas para a obtenção da população $F_{2}$, denominada população GH. Plantas ao acaso desta população foram autofecundadas, por quatro gerações, até a obtenção de linhagens $\mathrm{S}_{4}$. Quatro linhagens de cada população foram cruzadas entre si no esquema de dialelo parcial interpopulacional, obtendo-se 16 híbridos experimentais.

Foram avaliados 27 tratamentos: os 16 híbridos experimentais obtidos, três híbridos comerciais (Safira, AG-221 e Guarani), quatro linhagens $S_{5}$ selecionadas da população SHS e quatro linhagens $S_{4}$ selecionadas da população $\mathrm{GH}$ em um delineamento experimental em blocos ao acaso, com quatro repetições e seis plantas por parcela.

A semeadura, em 20-7-06, foi feita em bandejas de poliestireno expandido de 128 células, com transplante em 8-8-06, no espaçamento de 1,0 $\mathrm{m}$ entre linhas e $0,5 \mathrm{~m}$ entre plantas. A adubação de cobertura foi efetuada semanalmente, com nitrato de cálcio $\left(2 \mathrm{~g} \mathrm{planta}^{-1}\right)$ a partir da primeira semana após o transplante, e com nitrato de potássio ( $3 \mathrm{~g}$ planta $\left.^{-1}\right)$ mais MAP $\left(1 \mathrm{~g} \mathrm{planta}^{-1}\right)$ e nitrato de cálcio $\left(1 \mathrm{~g} \mathrm{planta}^{-1}\right)$ a partir do início da frutificação. Cada planta foi tutorada individualmente, eliminando-se todas as brotações e flores até o $5 .^{\circ}$ nó da haste principal, e a desbrota dos ramos laterais (após o $6{ }^{\circ}$ nó da haste principal) entre a segunda e terceira folhas. Retirou-se o meristema apical da planta quando esta atingiu a altura do arame (cerca de 1,80 $\mathrm{m}$ de altura). As características avaliadas foram: número de frutos total por planta, número de frutos comerciais (sem defeitos aparentes) por planta, massa total de frutos por planta, massa comercial de frutos por planta e porcentagem de frutos comerciais. O período de colheita foi de 25-9-06 a 6-11-06.

Foram realizadas as análises de variância para cada característica. As médias das linhagens e dos híbridos foram agrupadas pelo teste de Scott \& Knott a $5 \%$, para verificar o potencial das linhagens e dos híbridos experimentais em relação aos híbridos comerciais. Também foram estimadas as heteroses (\%) em relação às médias dos genitores e a heterobeltiose (superioridade do híbrido em relação ao genitor superior).

\section{RESULTADOS E DISCUSSÃO}

Para as características número total de frutos por planta, massa total de frutos por planta e massa comercial de frutos por planta não houve diferença entre os híbridos Safira e Guarani. Para número de frutos comerciais por planta, o híbrido Guarani foi superior aos híbridos Safira e AG-221. O híbrido AG221 foi inferior tanto ao Guarani como ao Safira para número de frutos total por planta, massa total e massa comercial de frutos (Tabela 1).

Para número total de frutos, as linhagens SHS3, SHS-7, GH-1 e os híbridos experimentais H31 e H74 foram inferiores aos híbridos comerciais Safira e Guarani. Já para número de frutos comerciais as linhagens SHS-3, SHS-7, GH-1 e GH-4 e também os híbridos experimentais H31, H44, H64, H71 e H74 foram inferiores ao híbrido comercial Guarani, porém quatro linhagens (SHS-4, SHS-6, GH-3 e GH-5) e 11 híbridos experimentais foram superiores aos híbridos Safira e AG-221 (Tabela 1).

Para massa total de frutos por planta, as linhagens SHS-4, SHS-6 e a maioria dos híbridos experimentais (exceto os híbridos H31, H44 e H64) foram superiores ao híbrido comercial AG-221 (Tabela 1).

Para massa comercial de frutos por planta, as linhagens SHS-3, SHS-4 e SHS-6 e a maioria dos híbridos experimentais (exceto H31, H44, H64 e H74) também foram superiores ao híbrido AG-221.

Para porcentagem de frutos comerciais não houve diferença entre os híbridos comerciais, linhagens e híbridos experimentais. Os valores observados foram superiores aos relatados por CARDOSO (2006) para os híbridos Safira e Guarani, que obteve $83 \%$ e $87 \%$ respectivamente.

Para número de frutos comerciais, $68,8 \%$ dos híbridos experimentais foram numericamente superiores aos híbridos comerciais Safira e AG-221; para massa comercial, $75 \%$ dos híbridos experimentais foram numericamente superiores ao híbrido comercial AG-221. Quanto à produção, destacam-se os híbridos experimentais H35 e H44 por serem numericamente superiores aos híbridos comerciais. 
Tabela 1. Número total de frutos por planta (NFT), número de frutos comerciais por planta (NFC), massa total de frutos (MT), massa comercial de frutos (MC) por planta e porcentagem de frutos comerciais (FC) em três híbridos comerciais, oito linhagens e 16 híbridos experimentais de pepino do grupo caipira. São Manuel (SP). UNESP-FCA, 2006

\begin{tabular}{|c|c|c|c|c|c|}
\hline Tratamentos & NFT & NFC & MT & $\mathrm{MC}$ & FC \\
\hline & 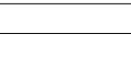 & 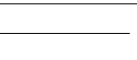 & 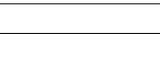 & 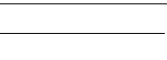 & $\%$ \\
\hline Safira & $15,58 \mathrm{a}$ & $13,74 \mathrm{~b}$ & 2062,16 a & $1849,70 \mathrm{a}$ & $86,90 \mathrm{a}$ \\
\hline AG-221 & $12,45 \mathrm{~b}$ & $11,28 \mathrm{~b}$ & $1703,37 \mathrm{~b}$ & $1565,99 \mathrm{~b}$ & $89,69 \mathrm{a}$ \\
\hline Guarani & 17,92 a & $16,77 \mathrm{a}$ & 2340,48 a & $2215,47 \mathrm{a}$ & $93,20 \mathrm{a}$ \\
\hline SHS-3 & $13,26 \mathrm{~b}$ & $12,64 \mathrm{~b}$ & $1906,17 \mathrm{~b}$ & 1865,70 a & $94,12 \mathrm{a}$ \\
\hline SHS-4 & $17,48 \mathrm{a}$ & $16,34 \mathrm{a}$ & $2298,44 \mathrm{a}$ & $2175,30 \mathrm{a}$ & $91,99 \mathrm{a}$ \\
\hline SHS-6 & 16,66 a & $14,99 \mathrm{a}$ & $2144,93 \mathrm{a}$ & $1970,92 \mathrm{a}$ & $89,46 \mathrm{a}$ \\
\hline SHS-7 & $10,54 \mathrm{~b}$ & $9,66 \mathrm{~b}$ & $1673,15 \mathrm{~b}$ & $1567,70 \mathrm{~b}$ & $89,91 \mathrm{a}$ \\
\hline GH-1 & $14,14 \mathrm{~b}$ & $11,44 \mathrm{~b}$ & $1588,31 \mathrm{~b}$ & $1343,68 \mathrm{~b}$ & $81,10 \mathrm{a}$ \\
\hline GH-3 & $17,71 \mathrm{a}$ & $14,56 \mathrm{a}$ & $1864,14 \mathrm{~b}$ & $1576,87 \mathrm{~b}$ & $81,61 \mathrm{a}$ \\
\hline GH-4 & $16,16 \mathrm{a}$ & $13,28 \mathrm{~b}$ & $1748,16 \mathrm{~b}$ & $1470,48 \mathrm{~b}$ & $82,84 \mathrm{a}$ \\
\hline GH-5 & $16,71 \mathrm{a}$ & $15,64 \mathrm{a}$ & $1825,89 \mathrm{~b}$ & $1722,61 \mathrm{~b}$ & $92,83 \mathrm{a}$ \\
\hline H31 & $14,55 \mathrm{~b}$ & $12,56 \mathrm{~b}$ & $1957,02 \mathrm{~b}$ & $1731,87 \mathrm{~b}$ & $85,02 \mathrm{a}$ \\
\hline H33 & 16,17 a & $14,54 \mathrm{a}$ & 2069,68 a & $1891,11 \mathrm{a}$ & $89,42 \mathrm{a}$ \\
\hline Н34 & $17,25 \mathrm{a}$ & $15,55 \mathrm{a}$ & $2191,99 \mathrm{a}$ & $2010,53 \mathrm{a}$ & $89,33 \mathrm{a}$ \\
\hline H35 & $19,05 \mathrm{a}$ & $17,05 \mathrm{a}$ & $2413,09 \mathrm{a}$ & 2197,69 a & $87,84 \mathrm{a}$ \\
\hline $\mathrm{H} 41$ & $16,56 \mathrm{a}$ & $14,50 \mathrm{a}$ & $2166,89 a$ & $1935,99 \mathrm{a}$ & $85,48 \mathrm{a}$ \\
\hline $\mathrm{H} 43$ & $19,44 \mathrm{a}$ & 16,68 a & 2305,57 a & 2018,62 a & $84,66 \mathrm{a}$ \\
\hline $\mathrm{H} 44$ & 16,18 a & $14,03 \mathrm{~b}$ & $1997,68 \mathrm{~b}$ & $1792,52 \mathrm{~b}$ & $86,54 \mathrm{a}$ \\
\hline $\mathrm{H} 45$ & $18,53 \mathrm{a}$ & $17,12 \mathrm{a}$ & $2256,01 \mathrm{a}$ & 2117,32 a & $91,50 \mathrm{a}$ \\
\hline H61 & $17,04 \mathrm{a}$ & $14,56 \mathrm{a}$ & 2149,85 a & 1876,71 a & $85,04 \mathrm{a}$ \\
\hline H63 & $18,77 \mathrm{a}$ & $16,83 \mathrm{a}$ & $2286,34 \mathrm{a}$ & 2094,37 a & $89,16 \mathrm{a}$ \\
\hline H64 & 15,86 a & $13,74 \mathrm{~b}$ & $1867,49 \mathrm{~b}$ & $1711,56 \mathrm{~b}$ & $86,43 \mathrm{a}$ \\
\hline H65 & $18,47 \mathrm{a}$ & $16,35 \mathrm{a}$ & 2271,43 a & 2051,18 a & $87,63 \mathrm{a}$ \\
\hline H71 & $16,00 \mathrm{a}$ & $13,50 \mathrm{~b}$ & 2192,16 a & 1911,68 a & $83,73 \mathrm{a}$ \\
\hline H73 & 17,66 a & $14,98 \mathrm{a}$ & $2254,33 \mathrm{a}$ & 1929,67 a & $83,80 \mathrm{a}$ \\
\hline $\mathrm{H} 74$ & $15,20 \mathrm{~b}$ & $12,79 \mathrm{~b}$ & 2028,13 a & $1736,14 \mathrm{~b}$ & $83,62 \mathrm{a}$ \\
\hline $\mathrm{H} 75$ & 18,66 a & 16,64 a & 2363,17 a & $2123,65 \mathrm{a}$ & $88,11 \mathrm{a}$ \\
\hline CV (\%) & 16,36 & 18,53 & 15,45 & 17,44 & 7,53 \\
\hline $\mathrm{F}$ & $2,44^{* *}$ & $2,13^{* *}$ & $2,12^{* *}$ & $2,01^{* *}$ & $1,18^{\mathrm{ns}}$ \\
\hline
\end{tabular}

Grupos de médias seguidas pela mesma letra, nas colunas, não diferem estatisticamente pelo teste de Scott \& Knott (5\%).

** Significativo pelo teste $\mathrm{F}$ ao nível de $1 \%$.

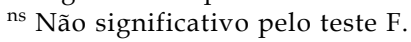

As estimativas de heterose em relação à média dos genitores para a característica número total de frutos variou de $-3,80$ a 36,94 , para número de frutos comerciais variou de $-5,27$ a 31,54 , para massa total de frutos de $-4,06$ a 35,08 , para massa comercial de frutos de $-1,67$ a 31,32 e para porcentagem de frutos comerciais variou de -6,03 a 4,24; os híbridos H75 e H71 destacaram-se com os maiores valores para número total de frutos, número de frutos comerciais, massa total por planta e massa comercial por planta (Tabela 2).
O híbrido mais produtivo (H35) não foi o de maior heterose (H75). Valores de heterose elevados por si só não são sinônimos de alta produção, pois a heterose retrata a superioridade (ou não) em relação à média dos genitores. Hormuzdi e More (1990) relataram heteroses variando de $4,6 \%$ a $247,3 \%$ para produção, em massa, de frutos maduros de pepino por planta. Entretanto, o híbrido com maior heterose $(247,3 \%)$ obtido por estes autores foi apenas o sétimo mais produtivo entre 24 híbridos avaliados. No caso destes autores, a heterose foi numericamente elevada 
pela baixa produção dos genitores. No presente experimento, um dos híbridos com maior heterose para produção de frutos (H71) não foi um dos mais produtivos, tendo sido, inclusive, inferior ao híbrido comercial Guarani e a vários híbridos experimentais para número de frutos comerciais (Tabela 2).

Tabela 2. Valores de heterose relativa de 16 híbridos experimentais de pepino do grupo caipira em relação à média dos genitores para as características número de frutos total por planta (NFT), número de frutos comerciais por planta (NFC), massa total de frutos (MT), massa comercial de frutos (MC) por planta e porcentagem de frutos comerciais (FC). São Manuel (SP), FCA/UNESP, 2006

\begin{tabular}{lrrrrr}
\hline Híbridos* & NFT & NFC & MT & MC & FC \\
\hline H31 & 6,20 & 4,32 & 12,00 & 7,93 & $-2,96$ \\
H33 & 4,42 & 6,91 & 9,79 & 9,87 & 1,77 \\
H34 & 17,27 & 19,98 & 19,97 & 20,53 & 0,96 \\
H35 & 27,12 & 20,58 & 29,32 & 22,49 & $-6,03$ \\
H41 & 4,74 & 4,39 & 11,50 & 10,03 & $-1,23$ \\
H43 & 10,48 & 7,96 & 10,78 & 7,60 & $-2,47$ \\
H44 & $-3,80$ & $-5,27$ & $-1,27$ & $-1,67$ & $-1,00$ \\
H45 & 8,39 & 7,07 & 9,40 & 8,64 & $-0,98$ \\
H61 & 10,65 & 10,17 & 15,17 & 13,24 & $-0,28$ \\
H63 & 9,22 & 13,90 & 14,06 & 18,07 & 4,24 \\
H64 & $-3,35$ & $-2,79$ & $-4,06$ & $-0,53$ & 0,33 \\
H65 & 10,70 & 6,76 & 14,41 & 11,07 & $-3,86$ \\
H71 & 29,66 & 27,96 & 34,43 & 31,32 & $-2,08$ \\
H73 & 25,02 & 23,70 & 27,46 & 22,73 & $-2,29$ \\
H74 & 13,86 & 11,51 & 18,56 & 14,29 & $-3,19$ \\
H75 & 36,94 & 31,54 & 35,08 & 29,09 & $-3,57$ \\
\hline
\end{tabular}

* Para os híbridos, o primeiro número refere-se à progênie da população SHS e o segundo número à progênie da população GH.

Em média, as estimativas obtidas para heterose foram elevadas, sendo superiores à maioria dos relatados na literatura. Filgueira et al. (1986) obtiveram heteroses para número de frutos variando de $-17,5 \%$ a $12,8 \%$ em híbridos de pepino caipira. Já RUBinO e WeHNER (1986) relataram heterose para produção total de frutos em pepino para conserva de $7,4 \%$ em ensaios desenvolvidos no verão e $5,1 \%$ na primavera. Também CARDOSO (2006) obteve elevadas heteroses (-6\% a 57\%) em híbridos experimentais de pepino caipira e CARDoso (2007) em híbridos experimentais de pepino japonês (-10\% a 59\%).

Dos 80 valores de heterose para características de produção, 60 foram positivos (Tabela 2), sendo, portanto, a maioria das vezes os híbridos superiores à média dos genitores. Se forem consideradas apenas as heteroses para número e massa de frutos por planta, das 64 estimativas, apenas oito foram negativas, ou seja, dos 16 híbridos experimentais apenas dois (H44 e H64) com heterose negativa. Godor et al. (2005), estudando uma das populações original [(Safira $\times$ Hatem $) \times$ Safira $F_{2} R_{1}$ ], observaram acentuada depressão por endogamia para produção de frutos imaturos, o que demonstra a importância da ação gênica não aditiva, que é a responsável pela heterose (VENKOVSKY e BARRIGA, 1992).

A heterose em relação à média dos genitores é um parâmetro genético que mostra a importância, ou não, dos efeitos gênicos não aditivos (dominância e epistase), geralmente associados à condição heterozigota (VenKOVSKY e BARRIGA, 1992). No entanto, comercialmente, um híbrido será vantajoso se for superior a ambos os genitores, conforme afirmação de Rubino e WeHner (1986). Por isto, decidiu-se calcular a heterobeltiose (Tabela 3).

Para heterobeltiose, o híbrido H35 teve o maior valor para número total de frutos. Para número de frutos comerciais e massa total por planta, o maior valor foi para o híbrido H71 e para massa comercial de frutos por planta o maior valor foi para o híbrido H75 (Tabela 3).

Tabela 3. Valores de heterobeltiose relativa de 16 híbridos experimentais de pepino do grupo caipira para as características número de frutos total por planta (NFT), número de frutos comerciais por planta (NFC), massa total de frutos (MT), massa comercial de frutos (MC) por planta e porcentagem de frutos comerciais (FC). São Manuel (SP), FCA/UNESP, 2006

\begin{tabular}{lrrrrc}
\hline Híbridos* & NFT & NFC & MT & MC & FC \\
\hline H31 & 2,90 & $-0,63$ & 2,67 & $-7,17$ & $-9,67$ \\
H33 & $-8,70$ & $-0,14$ & 8,58 & 1,36 & $-4,99$ \\
H34 & 6,75 & 17,09 & 14,99 & 7,76 & $-5,09$ \\
H35 & 14,00 & 9,02 & 26,59 & 17,79 & $-6,67$ \\
H41 & $-5,26$ & $-11,26$ & $-5,72$ & $-11,00$ & $-7,08$ \\
H43 & 9,77 & 2,08 & 0,31 & $-7,20$ & $-7,97$ \\
H44 & $-7,44$ & $-14,14$ & $-13,09$ & $-17,60$ & $-5,92$ \\
H45 & 6,01 & 4,77 & $-1,85$ & $-2,67$ & $-1,43$ \\
H61 & 2,28 & $-2,87$ & 0,23 & $-4,78$ & $-4,94$ \\
H63 & 5,99 & 12,27 & 6,59 & 6,26 & $-0,34$ \\
H64 & $-4,80$ & $-8,34$ & $-12,93$ & $-13,16$ & $-3,39$ \\
H65 & 10,53 & 4,54 & 5,90 & 4,07 & $-5,60$ \\
H71 & 13,15 & 18,01 & 31,02 & 21,94 & $-6,87$ \\
H73 & $-0,28$ & 2,88 & 20,93 & 22,37 & $-6,80$ \\
H74 & $-5,94$ & $-3,69$ & 16,02 & 10,74 & $-7,00$ \\
H75 & 11,67 & 6,39 & 29,43 & 23,28 & $-5,08$ \\
\hline
\end{tabular}

* Para os híbridos, o primeiro número refere-se à progênie da população SHS e o segundo número à progênie da população $\mathrm{GH}$. 
Das heterobeltioses, $50,0 \%$ também foram positivas, visto que os híbridos geralmente foram superiores ao genitor mais produtivo. Conseqüentemente, não seria interessante a utilização de uma linhagem de pepino, destas populações estudadas, diretamente como cultivar comercial, ao contrário do relatado por alguns autores (RUBINO e WEHNER, 1986; ROBINSON, 1999).

Já para porcentagem de frutos comerciais, todos os valores foram negativos (Tabela 3 ), ou seja, sempre o genitor superior foi melhor que o híbrido. Porém, o maior valor foi de apenas $9,67 \%$.

\section{CONCLUSÕES}

1. Foram obtidos híbridos experimentais tão produtivos quanto os híbridos comerciais, destacandose os híbridos H35 e H43.

2. A maioria dos híbridos foi superior às linhagens, resultando em elevados valores para heterose para produção de frutos. O híbrido H71 foi o de maior heterose quando comparado ao genitor superior.

\section{AGRADECIMENTOS}

À FAPESP pela de bolsa de doutorado concedida à primeira autora (processo $\mathrm{n}^{\circ} 03 / 12368-0$ ).

\section{REFERÊNCIAS}

BRIM, C.A. A modified pedigree method of selection in soybeans. Crop Science, Madison, v.6, p.220, 1966.

CAÑIZARES, K.A.L. A cultura de pepino. In: GOTO, R.; TIVELLI, S.W. Produção de hortaliças em ambiente protegido: condições subtropicais. Fundação Editora UNESP: São Paulo, 1998. p.195-223.

CARDOSO, A.I.I. Dialelo entre linhagens de uma população de pepino caipira. Horticultura Brasileira, Brasília, v.24, n.2, p.259-263, 2006.

CARDOSO, A.I.I. Avaliação de linhagens e híbridos experimentais de pepino do grupo varietal japonês sob ambiente protegido. Bragantia, Campinas, v.66, n.3, p.473479, 2007.

CRAMER, C.S.; WEHNER, T.C. Little heterosis for yield and yield components in hybrids of six cucumber inbreds. Euphytica, Wageningen, v.110, n.2, p.99-108, 1999.

CUI, H.W.; QI, Y.T.; LIU, J.H.; REN, Z.B. Correlation between parents and $\mathrm{F} 1$ progeny in earliness, heterosis and the estimation of traits limits of parents. Report Cucurbit Genetics Cooperative, Maryland, n.15, p.13-16, 1992.
DELANEY, D.E.; LOWER, R.L. Generation means analysis of plant characters in crosses between two determinate cucumber lines and Cucumis sativus var. hardwickii. Journal of the American Society for Horticultural Science, Alexandria, v.112, n.4, p.707-711, 1987.

FEHR, W.R. Principles of cultivar development: theory and thecnique. New York: Mcmillan Publishing, 1987. p. 536.

FILGUEIRA, F.A.R.; GIORDANO, L.B.; FERREIRA, P.E.; DELLA VECCHIA, P.T. Avaliação de híbridos F1 de pepino do tipo caipira. Horticultura Brasileira, Brasília, v.4, n.1, p.17-20, 1986.

GHADERI, A.; LOWER, R.L. Heterosis and phenotypic stability of F1 hybrids in controlled environment. Journal of the American Society for Horticultural Science, Alexandria, v. 103, n.3, p.275-278, 1978.

GODOY, A.R.; OVIEDO, V.R.S.; CARDOSO, A.I.I. Análise endogâmica de uma população de pepino caipira. Horticultura Brasileira, Brasília, v.23, n.3, p.785-788, 2005.

HORMUZDI, S.G.; MORE, T.A. Heterosis studies in cucumber. Indian Journal of Horticulture, Bangalore, v.46, p.73-79, 1990.

LI, J.W.; LI, J.W.; WEI, Z.D. Genetic analysis for major agronomic characters in cucumber (Cucumis sativus L.). Acta Horticulturae, The Hague, n.402, p.388-391, 1995.

LOWER, R.L.; EDWARDS, M.D. Cucumber breeding. In: BASSET, M.J., ed. Breeding vegetable crops. Westport: Avi Publishing, 1986. p.173-207.

MALUF, W.R. Heterose e emprego de híbridos F1 em hortaliças. In: RECURSOS genéticos e melhoramento Plantas. Rondonópolis: Fundação MT, 2001. p.237-356.

ROBINSON, R.W. Rationale and methods for producing hybrid cucurbit seed. Journal of New Seeds, Binghanton, v.1, p.1-47, 1999.

ROBINSON, R.W.; DECKER-WALTERS, D.S. Cucurbits. Cambridge: CAB International, 1999. 226p.

RUBINO, D.B.; WEHNER, T.C. Effect of inbreeding on horticultural performance of lines developed from an openpollinated cucumber population. Euphytica, Wageningen, v.35, p.459-464, 1986.

VENCOVSKY, R.; BARRIGA, P. Genética biométrica no fitomelhoramento. Ribeirão Preto: Revista Brasileira de Genética, 1992. 496p.

VIGGIANO, J. Hortaliças: cultivares e sementes. Horticultura Brasileira, Brasília, v.12, n.2, p.252-254, 1994.

WHITAKER, T.W.; DAVIS, G.N. Cucurbits: Botany, Cultivation and Utilization. New York: Interscience Publishers, 1962. 250p. 